\title{
Congenital Trifurcation of the Trachea
}

\author{
Kiarash Taghavi ${ }^{1}$ David Perry ${ }^{2,3}$ James K. Hamill ${ }^{1}$ \\ 1 Department of Paediatric Surgery: Thoracic, Urology, GI/HPB, \\ Starship Children's Health, Auckland, New Zealand \\ 2 Department of Radiology, Starship Children's Health, Auckland, \\ New Zealand \\ ${ }^{3}$ National Women's Hospital, Auckland, New Zealand
}

\begin{abstract}
Address for correspondence Dr. Kiarash Taghavi, MBChB, PGDip Surg Anat(Dist), PGDip Paed, Paediatric Surgical Registrar, Department of Paediatric Surgery, Thoracic, Urology, GI/HPB, Starship Children's Health, Private Bag 92 024, Auckland Centre, Auckland 1142, New Zealand (e-mail: kiarash.taghavi@gmail.com).
\end{abstract}

Eur J Pediatr Surg Rep 2014;2:35-37.

\section{Abstract \\ Keywords \\ - ectopic bronchus \\ - tracheal trifurcation \\ - congenital lung disease}

"Tracheal trifurcation" is a veritable and rare finding. We illustrate a unique case that demonstrates the complexity and broad variability that congenital tracheobronchial anomalies can take. Appreciation of these is important at intubation, bronchoscopy, and surgery.

\section{Introduction}

"Tracheal trifurcation" with an ectopic bronchus or foregut fistula is exceedingly rare. A "tracheal bronchus" is uniformly found within $2 \mathrm{~cm}$ of the carina supplying the right upper lobe. ${ }^{1}$ In children undergoing bronchoscopy for respiratory symptoms, an ectopic bronchus was found in $2 \%$ of the cases. ${ }^{2}$ These may be asymptomatic or associated with bronchiectasis, focal emphysema or cystic lung malformations. ${ }^{3}$ Implications at intubation, bronchoscopy, and surgery can be complex. $^{4}$

\section{Case Presentation}

A 2-year-old girl suffered right lower lobe pneumonia. On resolution, she remained symptomatic with a dry cough and reduced exercise tolerance. She had an antenatal history of a right echogenic lung mass. Computed tomographic imaging at 3 months demonstrated tracheal trifurcation at the carina with normal vascular anatomy ( - Fig. 1). Flexible bronchoscopy confirmed bronchomalacia of the ectopic bronchus (-Fig. 2).

At thoracotomy, a single artery supplied the lower lobe draining via its own inferior pulmonary vein (-Fig. 3 ). The right lower lobe was excised and histology confirmed bronchiectasis. Recovery was uneventful and at 3-month follow-up exercise tolerance and energy levels had improved.

\section{Discussion}

To our knowledge, the only previously reported case of an ectopic bronchus supplying the right lower lobe (as opposed to the upper lobe) was associated with a sequestration. ${ }^{5} \mathrm{~A}$ rare "bridging bronchus" crossing the mediastinum has previously been reported, representing an origin of the right lower lobe bronchus from the left bronchial tree. ${ }^{6}$

The relationship between esophageal atresia and tracheal bronchus has been demonstrated in the Adriamycin rat model, in which approximately one-fifth had a tracheal bronchus. ${ }^{7}$ This corresponds with case reports of VACTERL children with tracheobronchial malformations ${ }^{8}$ and highlights the need for comprehensive evaluation of the tracheobronchial tree in esophageal atresia before repair is undertaken. ${ }^{9}$ Although it is suspected that these malformations may carry an increased malignant risk this has not been quantified in the literature. There have been multiple cases of lung cancer (squamous cell carcinoma, adenocarcinoma, small cell carcinoma, and bronchial carcinoid) associated with a tracheal bronchus, but these have generally been in adults over 50 years of age with a history of smoking or other lung pathology. ${ }^{10-18}$ received

May 26, 2013

accepted after revision

July 11, 2013

published online

September 9, 2013
DOI http://dx.doi.org/

10.1055/s-0033-1353367. ISSN 2194-7619. (c) 2014 Georg Thieme Verlag KG Stuttgart · New York
License terms

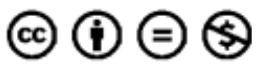




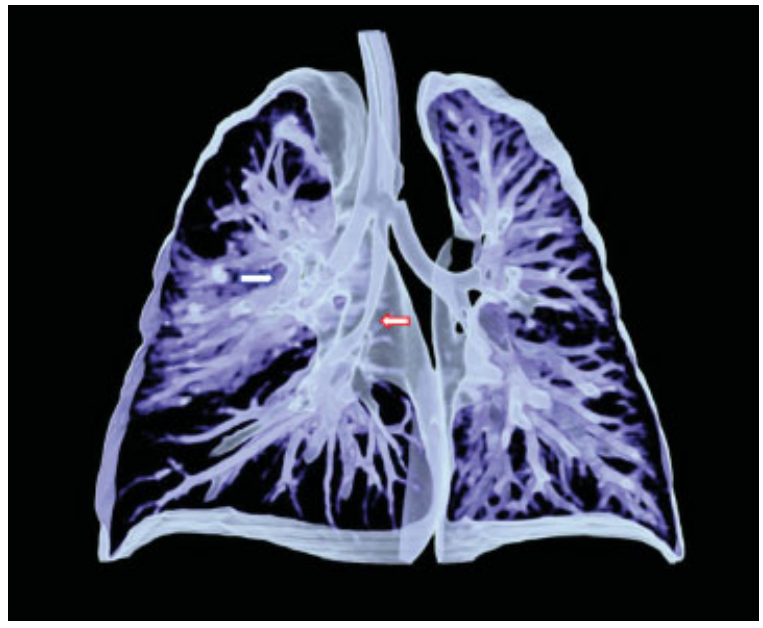

Fig. 1 Three-dimensional reconstruction of computed tomographic images showing the trifurcation with an ectopic right lower lobe bronchus with a bronchomalacic portion (red arrow). There was also a dilated bronchus (blue arrow) distal to an atretic apicoposterior upper lobe bronchus.
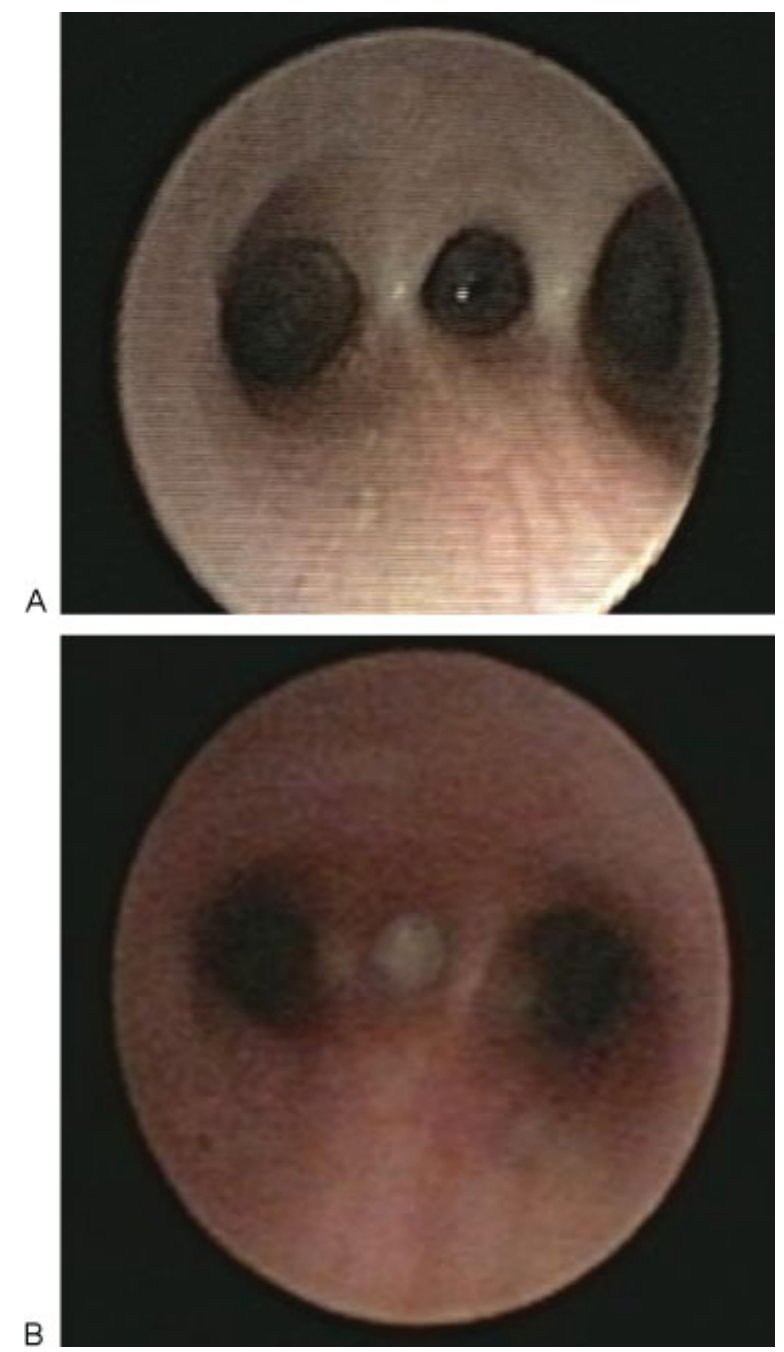

Fig. 2 Image A was taken at initial bronchoscopy confirming the diagnosis of ectopic tracheal bronchus that entered between the two main stem bronchi. Image B was taken following recovery from pneumonia showing persistent pus containing Haemophilus influenzae.

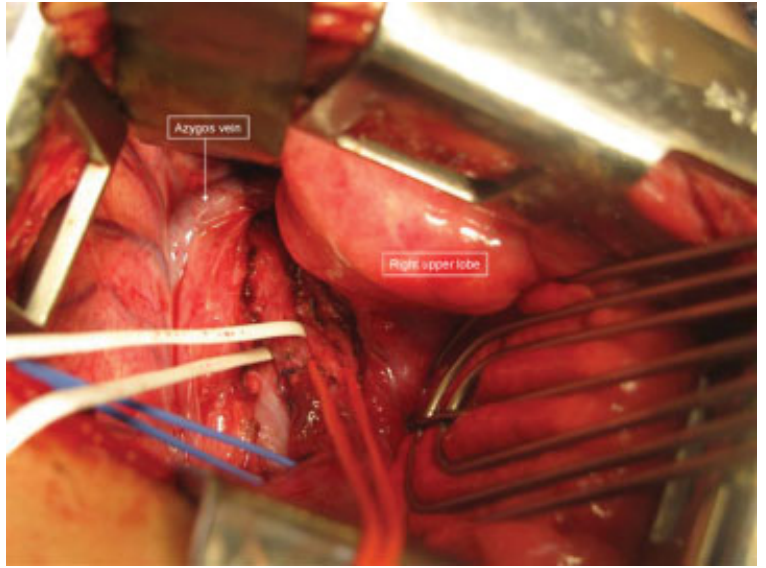

Fig. 3 Intraoperative photograph with the ectopic right lower lobe bronchus (white loop) with its respective artery (red loop) and vein (blue loop).

\section{Conflict of Interest}

None.

\section{References}

1 Ghaye B, Szapiro D, Fanchamps JM, Dondelinger RF. Congenital bronchial abnormalities revisited. Radiographics 2001;21(1): 105-119

2 McLaughlin FJ, Strieder DJ, Harris GB, Vawter GP, Eraklis AJ. Tracheal bronchus: association with respiratory morbidity in childhood. J Pediatr 1985;106(5):751-755

3 Ritsema GH. Ectopic right bronchus: indication for bronchography. AJR Am J Roentgenol 1983;140(4):671-674

4 Ramamani M, Ponnaiah M, Bhaskar S, Rai E. An uncommon cause of unanticipated difficult airway. Paediatr Anaesth 2009;19(6): 643-645

5 de Lagausie P, Van Den Abbeele T, Elmaleh M, Ferkadji L, Maintenant J, Aigrain Y. Bronchial trifurcation in a congenital pulmonary venolobar syndrome. Pediatr Pulmonol 2001;31(4): 303-305

6 Gonzalez-Crussi F, Padilla LM, Miller JK, Grosfeld JL. "Bridging bronchus". A previously undescribed airway anomaly. Am J Dis Child 1976;130(9):1015-1018

7 Xia H, Otten C, Migliazza L, Diez-Pardo JA, Tovar JA. Tracheobronchial malformations in experimental esophageal atresia. J Pediatr Surg 1999;34(4):536-539

8 Kanu A, Tegay D, Scriven R. Bronchial anomalies in VACTERL association. Pediatr Pulmonol 2008;43(9):930-932

9 Usui N, Kamata S, Ishikawa S, et al. Anomalies of the tracheobronchial tree in patients with esophageal atresia. J Pediatr Surg 1996;31(2):258-262

10 Kuo CW, Lee YC, Perng RP. Tracheal bronchus associated with lung cancer: a case report. Chest 1999;116(4):1125-1127

11 Kim J, Park C, Kim H, Lee KS. Surgical resection of lung cancer originating in a tracheal bronchus. Ann Thorac Surg 1998;66(3): 944-946

12 Uchikov P, Nikolov P. [A case of carcinoma developing from the base of an anomalous tracheal bronchus]. Khirurgiia (Sofiia) 1974; 27(4):319-320

13 Moriya H, Kato H, Togawa T. Small cell lung cancer arising in an abnormal bronchus. Jpn J Chest Dis. 1985;44:1035-1039

14 Patrinou V, Kourea H, Dougenis D. Bronchial carcinoid of an accessory tracheal bronchus. Ann Thorac Surg 2001;71(3): 1034-1035 
15 Sen S, Sentürk E, Pabuşçu E, Sen S. [Upper lobectomy for lung cancer with true tracheal bronchus: a unique presentation]. Arch Bronconeumol 2010;46(6):332-334

16 Sato M, Hasegawa S, Shoji T, Wada H. Tracheobronchoplasty for resection of lung cancer arising from a tracheal bronchus. Ann Thorac Surg 2002;73(1):310-312
17 Okubo K, Ueno Y, Isobe J. Upper sleeve lobectomy for lung cancer with tracheal bronchus. J Thorac Cardiovasc Surg 2000;120(5): 1011-1012

18 Metin M, Sayar A, Turna A, Gürses A. Tracheal bronchus obliterated with bronchial carcinoid. Eur J Cardiothorac Surg 2002; 21(1):155 